\title{
Analysis of the Variation of Thermal Conductivity of Rigid Polyisocyanurate Foam (PIR) in The Context of Aging
}

\author{
Tomas Makaveckas, Raimondas Bliūdžius and Aurelija Levinskytė \\ Institute of Architecture and Construction, Kaunas University of Technology, Tunelio 60, LT-44405 \\ Kaunas, Lithuania, asi@ktu.lt
}

\begin{abstract}
For most building insulation materials, dependency of the thermal conductivity on temperature is close to linear, and it increases with rising materials temperature, but the thermal conductivity of the polyisocyanurate foam (PIR) increases in the lower temperature range, so the heat transfer through the partition insulated with this material is increased in the cold season. The thermal conductivity of PIR also increases during the aging process, especially during the later operating period, which is not covered by the standard aging procedure used to determine the declared thermal conductivity value. Also, there is a lack of information how PIR reacts to the certain temperatures and other climate conditions, and how fast it loses its thermal properties. The aim of this experimental research was to analyse the change of the thermal conductivity depending on aging temperature. 30, 50 mm thick PIR samples were prepared for the test, and the thermal conductivity of all specimens was measured at the standard conditions prior to the start of the test using the heat flow meter FOX 314 , and again after each stage of aging, when the samples were kept at the certain temperature for 21 days. The results showed that the thermal conductivity of PIR increases more (up to $10 \%$ ) when kept at higher temperatures $\left(+50^{\circ} \mathrm{C}\right.$, and $\left.+70^{\circ} \mathrm{C}\right)$, and after specimens undergo negative temperatures $\left(-18^{\circ} \mathrm{C}\right)$ it has a minor influence to the change of thermal conductivity of PIR.
\end{abstract}

Keywords: Polyisocyanurate Foam Insulation, Thermal Conductivity, Aging.

\section{Introduction}

Thermal insulation for buildings is used to create indoor thermal comfort using as little thermal energy as possible. The thermal insulation in building envelope extends the periods of indoor thermal comfort, and by keeping buildings with smaller temperature fluctuations, it helps to preserve the integrity of building structures, increasing their lifetime (Berardi and Naldi, 2017). Long-term performance is an important consideration for choosing the best insulation material for each application (Alvey et al., 2017). Change of thermal conductivity over time has been extensively studied for different thermal insulation materials such as mineral wool, expanded polystyrene foam (EPS), and extruded polystyrene foam (XPS) which are used in building insulation layer (Berardi, 2017; Khoukhi et al., 2016). Current environmental issues require intensive research on energy efficiency and energy savings in buildings to reduce consumption of conventional fuel and $\mathrm{CO}_{2}$ emissions that generate greenhouse effect (Paraschiv et al., 2017). Therefore, the use of rigid polyisocyanurate-polyurethane foam (PIR/PUR) in construction has recently significantly increased due to its excellent mechanical properties and low thermal conductivity (Jin et al., 2014). However, changes in the thermal properties of this thermal insulation material due to environmental influences have not been sufficiently investigated.

Polyurethanes are urethane bonded polymers and are made by reacting diisocyanates with polyols, and some additional chemicals and catalysts. Polyurethane foams are one of the most effective thermal insulation materials because blowing agent gas with extremely low thermal 
conductivity is trapped in the closed porous structure (Zhang et al., 2017). Thermal conductivity of this material at its standard measurement temperature is low due to the blowing agent trapped in the insulation cells, which is more inert and has a lower thermal conductivity than air. This reduces heat transfer through the cells by thermal conduction and convection, however, if the temperature falls below the condensation point of the blowing agent, the gas condenses in the cell space, and since the liquid phase of the blowing agent is more conductive than its gaseous phase, the heat transfer increases (Berardi and Naldi, 2017). These phenomena result in a continuous reduction of thermal resistance (i.e. aging) of the foam over period of time, resting to a long-term equilibrium value (Mukhopadhyaya et al., 2004) For a gas to function as an insulating gas in the cell of polyurethane and polyisocyanurate foam, it must be in a gaseous state (Bogdan et al., 2005). Bogdan et al. (2005) gives few diagrams showing thermal conductivity of gases versus temperature. Few researchers showed that the thermal conductivity of porous insulating materials strongly depend on their moisture content (Berardi, 2019).

Tests have shown that the thermal resistance $R,\left(\mathrm{~m}^{2} \cdot \mathrm{K} / \mathrm{W}\right)$ of PIR decreases when the ambient temperature drops below $0{ }^{\circ} \mathrm{C}$, reaching a peak when the material temperature is like the indoor air temperature (i.e. between $2.2{ }^{\circ} \mathrm{C}$ and $42.2{ }^{\circ} \mathrm{C}$ ). During the winter, when the temperature falls below $0{ }^{\circ} \mathrm{C}$ and the time when a PIR-insulated roof is heated by the sun and the material temperature rises higher than $45^{\circ} \mathrm{C}$, the $R$-value of the thermal resistance decreases (Building Science Corporation, 2013). However, Finch et al. (2014) noted that in roof assembly using other insulation materials, such as mineral wool, together with PIR may significantly improve the effective R-value of the polyisocyanurate as it keeps it near optimum temperatures (near
room temperature). Berardi (2019) performed an experiment with several foam materials
showing that the aging of the foams and the operating temperatures have higher impacts on the
polyisocyanurates than on polyurethanes. His study showed that different aging mechanisms
impact mainly the polyisocyanurate which increased their effective tbermal conductivity
significantly.

Standard methods for predicting the change in thermal properties of polyurethane foam:

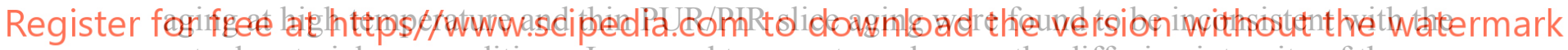
actual material use conditions. Increased temperature changes the diffusion intensity of the gas trapped in the pores of the material in a non-uniform manner (pentane-foamed material gases are $\mathrm{CO}_{2}$, air, and different pentane isomers) (Christian et al., 1995; Stovall et al., 2013). Thin slicing and weighing do not appreciate the fact that the surface layers of PIR with facing are denser than the inner layers (Singh et al., 2003). The main standard for rigid polyurethane foam (PUR/PIR) products is EN 13165:2012+A2:2016, and the aged value can be determined in one of two ways according to this standard. The first is the thermal conductivity measured after 175 days aging at $70{ }^{\circ} \mathrm{C}$, with the addition of safety factor which depends on the type of facing, the blowing agent of the foam and the thickness of the product. The safety factor may be adjusted on the basis of a comparison between the aged values at $23{ }^{\circ} \mathrm{C}$ and $70{ }^{\circ} \mathrm{C}$. The second is the thermal conductivity measured after 21 days of exposure at $70{ }^{\circ} \mathrm{C}$ with addition of a fixed increment. Fixed increment depends mainly on the type of facing and is different for different blowing agents.

As PIR thermal insulation material is rapidly gaining popularity in the Northern Europe, which has a wide range of ambient air temperatures, it is important to investigate its thermal properties under operating conditions, and to predict the influence of temperature, and aging effects on the thermal properties of buildings insulated with PIR. 


\section{Research Methodology}

\subsection{Sampling and Sample Preparation for Testing}

In this experiment, samples are aged like in the standard fixed increment procedure, but the samples are used at full thickness as fabricated, i.e. without cutting a $20 \mathrm{~mm}$ sample from the core of the product. This is done to find out how the entire product is aging at different temperatures and how the (non)presence of a facing affects the change in thermal conductivity. For this experimental study, PIR specimens were obtained from the producer. The dimensions of the specimens are $300 \times 300 \mathrm{~mm}$, thicknesses 30 and $50 \mathrm{~mm}$. Samples of each thickness are taken from products of three different production dates. There are three types of specimens for each date of production: the first specimen is with a factory-made composite non-diffusion facing; the second sample is sealed with a diffusion-tight film from all sides; the third sample has its facing removed. Products are stored at $(23 \pm 3){ }^{\circ} \mathrm{C}$ and $(50 \pm 10) \%$ relative humidity for at least 16 hours before cutting. Prior to thermal treatment, the value of the thermal conductivity of each sample is measured using FOX 314 Heat Flow Meter in conformity to ISO 8301. Two tests are performed in parallel: first - successive effects of temperature on specimens, maintaining the same specimens at different temperatures and measuring their thermal conductivity after each step corresponding to the temperature environment over the year; second - measuring different specimens after storing in different temperature environments, to determine certain temperature impact on thermal conductivity.
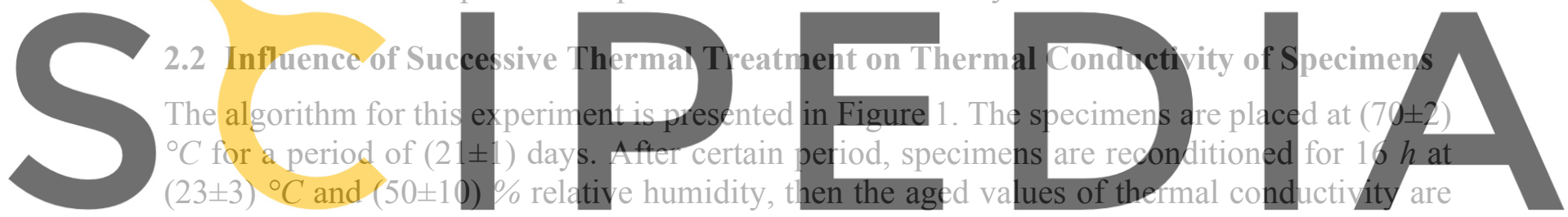
determined using FOX 314 Heat Flow Meter. The measured value is compared with the value

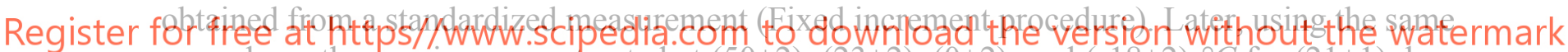
procedures the specimens are treated at $(50 \pm 2),(23 \pm 2),(0 \pm 2)$, and $(-18 \pm 2){ }^{\circ} \mathrm{C}$ for $(21 \pm 1)$ day, and their thermal conductivity is measured after each stage. Table 1 shows the mean values of the measured thermal conductivity before and after each exposure at different temperature conditions.

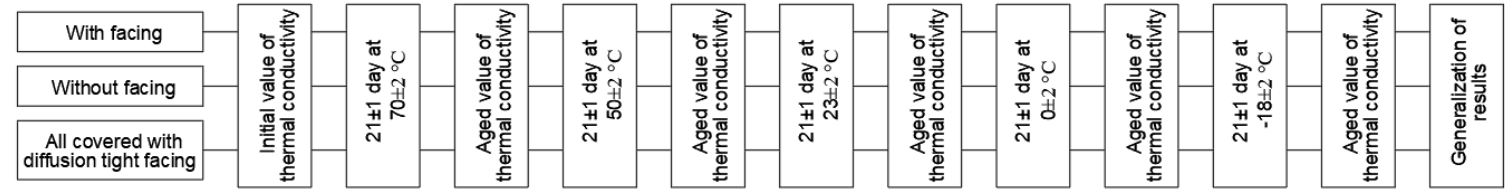

Figure 1. Algorithm of the experiment. 
Table 1. Average thermal conductivity values after successive aging in different temperature conditions.

\begin{tabular}{|c|c|c|c|c|c|c|c|}
\hline \multirow{2}{*}{$\begin{array}{c}\text { Thickness, } \\
m m\end{array}$} & Type of facing & \multicolumn{5}{|c|}{$\lambda$ value, $W / m \cdot K$} \\
\cline { 3 - 8 } & & Initial & Aged at $70{ }^{\circ} \mathrm{C}$ & Aged at $50{ }^{\circ} \mathrm{C}$ & Aged at $23{ }^{\circ} \mathrm{C}$ & Aged at $0{ }^{\circ} \mathrm{C}$ & Aged at $-18{ }^{\circ} \mathrm{C}$ \\
\hline \multirow{3}{*}{30} & Diffusion tight/covered & 0,0206 & 0,0224 & 0,0226 & 0,0228 & 0,0226 & 0,0219 \\
\cline { 2 - 8 } & Diffusion tight & 0,0204 & 0,0219 & 0,0220 & 0,0221 & 0,0221 & 0,0222 \\
\cline { 2 - 8 } & Without facing & 0,0208 & 0,0238 & 0,0243 & 0,0243 & 0,0241 & 0,0232 \\
\hline \multirow{3}{*}{50} & Diffusion tight/covered & 0,0205 & 0,0219 & 0,0220 & 0,0219 & 0,0219 & 0,0222 \\
\cline { 2 - 8 } & Diffusion tight & 0,0206 & 0,0220 & 0,0220 & 0,0221 & 0,0221 & 0,0222 \\
\cline { 2 - 8 } & Without facing & 0,0207 & 0,0230 & 0,0232 & 0,0231 & 0,0230 & 0,0232 \\
\hline
\end{tabular}

\subsection{Influence of Particular Thermal Treatment on Thermal Conductivity of Specimens}

This experiment is conducted to investigate the effect of ambient temperature conditions on the thermal conductivity of specimens. The specimens are kept at different temperature environments: $(70 \pm 2),(50 \pm 2),(23 \pm 2)$ and $(-18 \pm 2){ }^{\circ} C$ for $(21 \pm 1)$ days, after which the specimens are reconditioned for $16 \mathrm{~h}$ at $(23 \pm 3){ }^{\circ} \mathrm{C}$ temperature and $(50 \pm 10) \%$ relative humidity, and the change in thermal conductivity is measured. The results of the measurements are given in Table 2.

Table 2. Thermal conductivity values after particular aging in different temperature conditions.
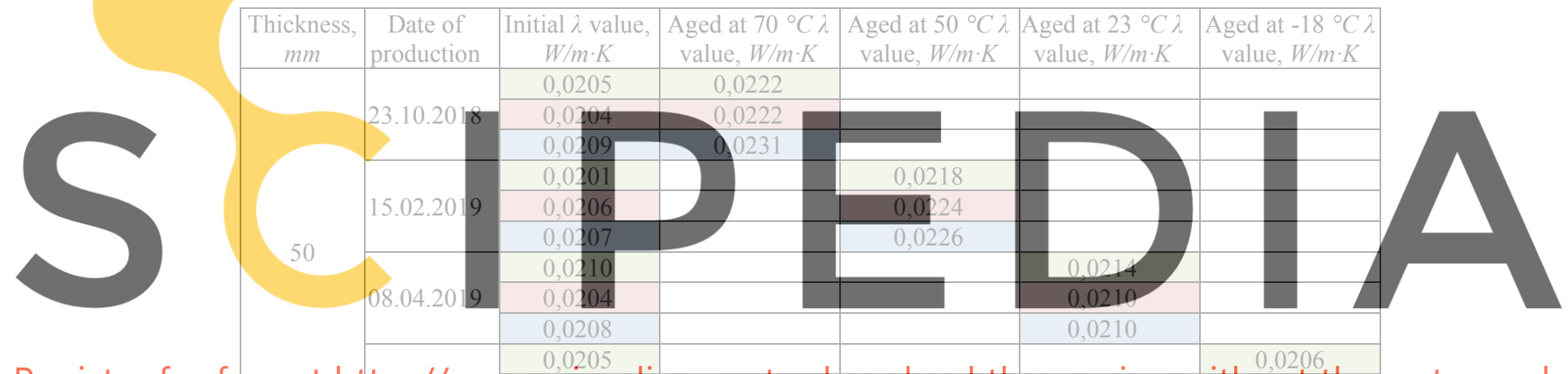

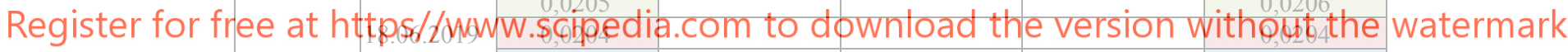

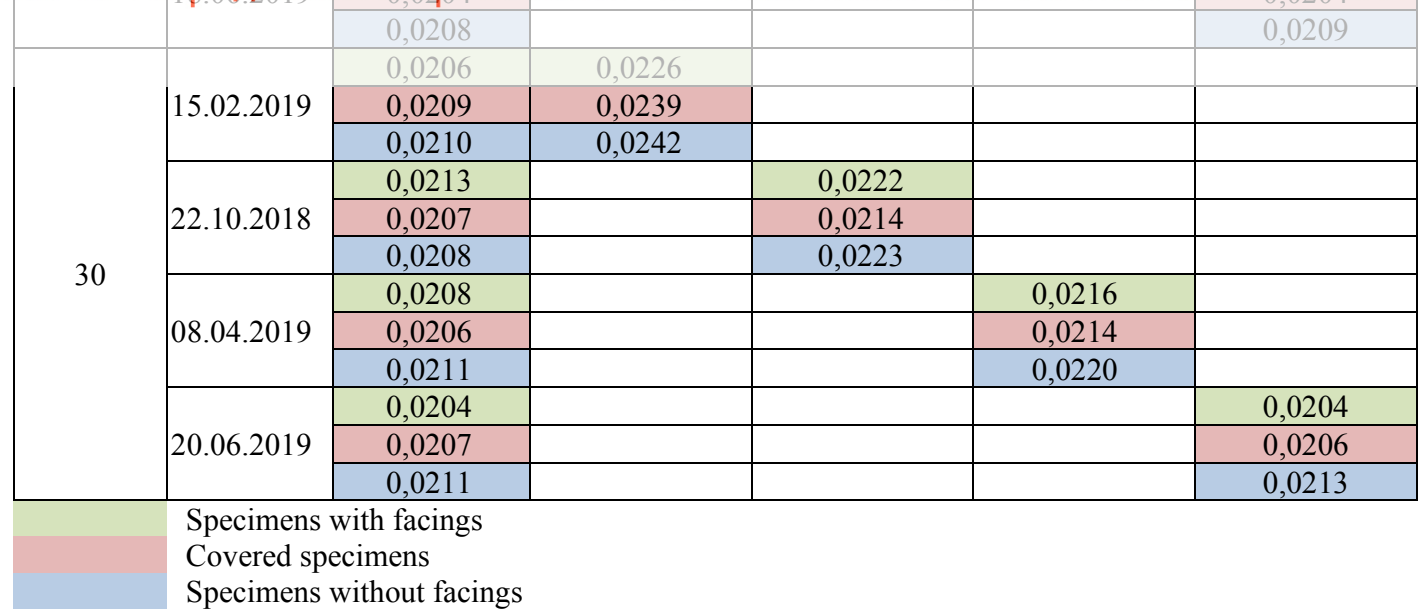

\section{Results and Discussion}

The thermal conductivity values of PIR specimens measured in both experimental studies were 
compared with the declared thermal conductivity value, which is determined by standard procedures, i.e. aging and measuring a $20 \mathrm{~mm}$ sample cut from the core of the product.

Figure 2 shows the thermal conductivity variation of $30 \mathrm{~mm}$ thick PIR specimens using a successive thermal treatment procedure. All types of specimens show a significant increase in thermal conductivity after heating at $70{ }^{\circ} \mathrm{C}$. This change could be explained by the intense diffusion of gas out of the material pores into the surrounding environment. It can be noticed, that when the same specimens are kept at a lower positive temperatures, the increase in the thermal conductivity is insignificant, while for specimens with facing it is close to linear. This indicates that the emission of gas into the environment at this stage is largely dependent on their movement from the inner layers of the material to the superficial layers. The thermal conductivity of the unfaced samples ceases to increase earlier than that of the faced samples, and it depends on the diffusion possibilities, which are limited by the facings.

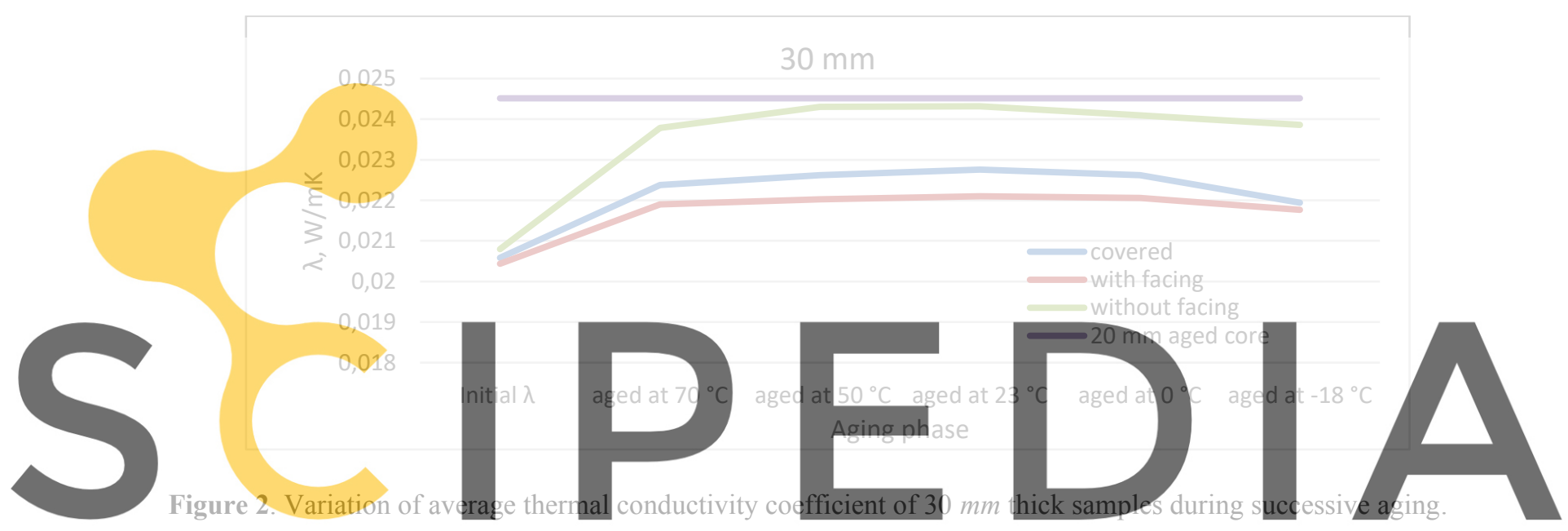

Register for The results af this experiment also show that the thermal conductivity of unfaced specimens at the average operating conditions is close to the declared thermal conductivity of the product, and significantly lower than that of the faced specimens. This shows that when standard procedure is applied, even for $30 \mathrm{~mm}$ thick products with facing thermal properties can be unreasonably degraded.

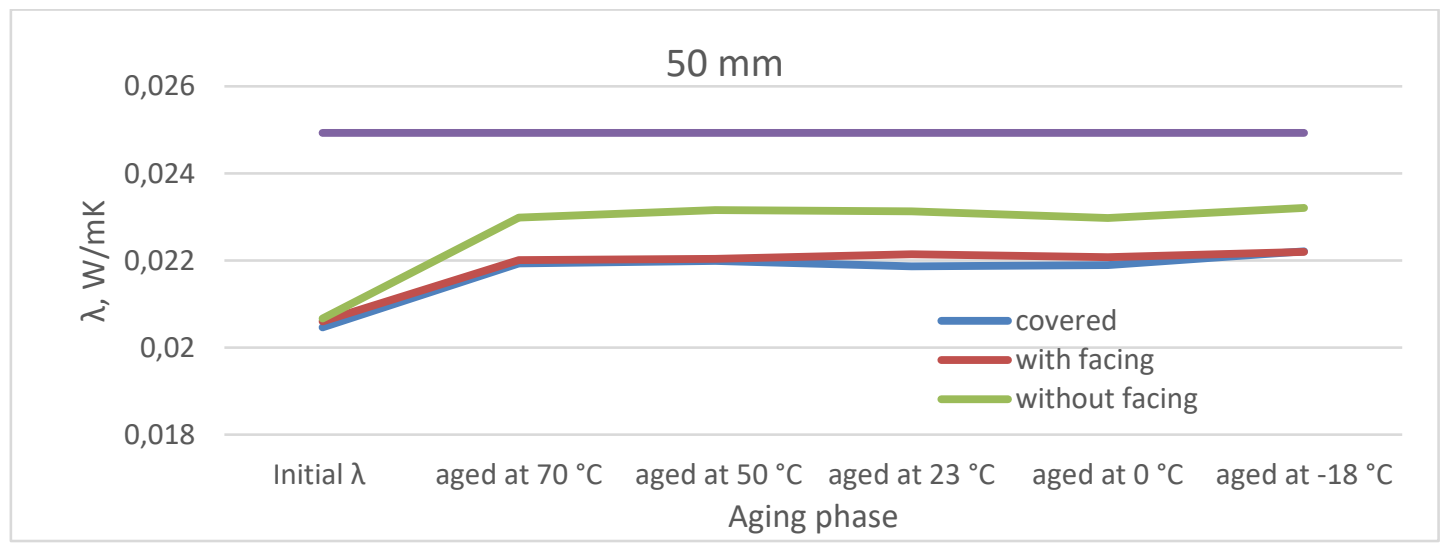

Figure 3. Variation of average thermal conductivity coefficient of $50 \mathrm{~mm}$ thick samples during successive aging. 
The tendency of the PIR thermal conductivity change is similar for $50 \mathrm{~mm}$ thick specimens (Figure 3). In this case, it has been found that the post-production side facings of the specimen do not affect its thermal conductivity because they do not ensure a gas-tight permeability. It can also be seen in this graph that the increase in the thermal conductivity of the specimens stabilized earlier (already after heating at $70{ }^{\circ} \mathrm{C}$ ), than that of the $30 \mathrm{~mm}$ thick specimens. This may be due to the larger lateral area of the test specimens, which could have released more gas during the same period. Examination of $50 \mathrm{~mm}$ thick specimens also showed that the thermal conductivity of the specimens with removed facing remains lower than that of the same $30 \mathrm{~mm}$ thick specimens during the successive aging. This difference may be due to the fact that the surface layers of the material are compacted to such an extent that they significantly stop the gas diffusion into the environment, and at the end of the experiment, the remaining gas concentrations in the pores of $50 \mathrm{~mm}$ thick specimens is higher than in the $30 \mathrm{~mm}$ thick specimens. Only further investigations could determine the effect of the thickness on the rate of gas diffusion and consequently on the increase in thermal conductivity for specimens with removed facing.


Register for free at https//www.scipedia.com to $70^{\circ} \mathrm{C}$

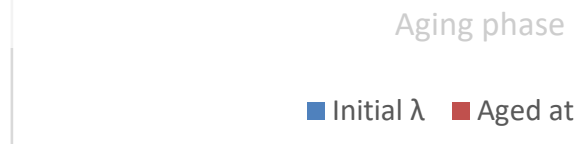

c)

Figure 4. Influence of temperature conditions on the thermal conductivity of PIR (50 $\mathrm{mm}$ sample: a) covered, b) with facing, c) without facing).

The influence of specific temperature environmental conditions on the variation of PIR thermal conductivity is presented in Figures 4 and 5. Analysing changes in the thermal conductivity of $50 \mathrm{~mm}$ thick specimens showed that temperatures $70{ }^{\circ} \mathrm{C}$ and $50{ }^{\circ} \mathrm{C}$ has the greatest influence. For both types of specimens with diffusion-tight facing, the thermal conductivity increases by $8-9 \%$ after exposure to higher temperatures $\left(50{ }^{\circ} \mathrm{C}, 70{ }^{\circ} \mathrm{C}\right)$, and to $11 \%$ for specimens with removed facings (Figure $4 \mathrm{c}$ ). This confirms the effect of diffusion of the gases, present in the pores of the material, on the thermal conductivity of the material. Exposure to negative temperatures $\left(-18^{\circ} \mathrm{C}\right)$ does not alter the thermal insulation properties of all specimens. 
Examination of $30 \mathrm{~mm}$ thick specimens showed that in all three cases aging at $70{ }^{\circ} \mathrm{C}$ had the greatest influence (up to 10-15\%) on their thermal conductivity (Figure 5). The influence of 50 ${ }^{\circ} \mathrm{C}$ on the thermal conductivity of the $30 \mathrm{~mm}$ samples with facings is smaller (only 3-4\%), while that of the samples without facings was slightly higher $-7 \%$ (Figure $5 \mathrm{c}$ ). As with $50 \mathrm{~mm}$ thick specimens, the change in the thermal conductivity of the $30 \mathrm{~mm}$ thick specimens is not affected by the negative temperature. This indicates that the gas condensation in the pores does not change the thermal properties of the material.

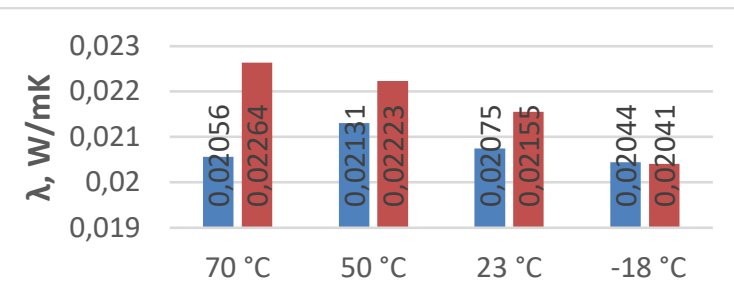

Aging phase

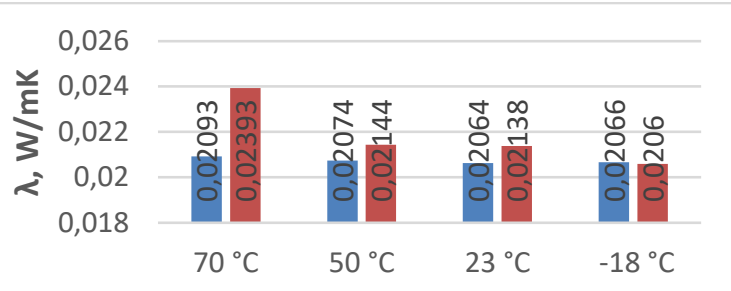

Aging phase

a)

b)

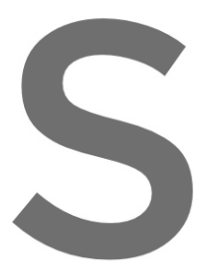

Figure 5. Influence of temperature
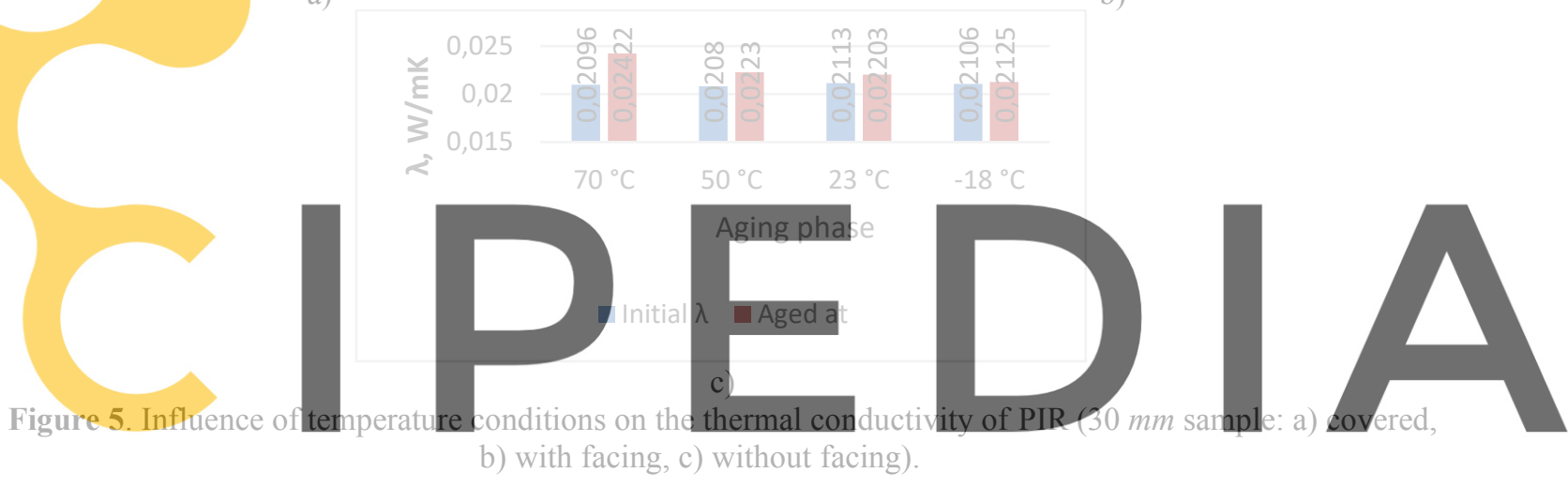

Register for free at https//www.scipedia.com to download the version without the watermark

The standard methodology for determining the declared value of the thermal conductivity of PIR, when a specimen is cut from the core of a product, does not meet the conditions of use of products faced with diffusion tight facings, and must be adjusted providing aging and measurement of the specimens with such facings.

- The thermal conductivity of PIR is mostly changed after storage at $70{ }^{\circ} \mathrm{C}$. The higher growth in thermal conductivity was measured for thinner specimens - $30 \mathrm{~mm}$. Experiments showed that the 21 days aging period at the high temperature is enough for the samples to have a thermal conductivity settling down. After storage at $-18{ }^{\circ} \mathrm{C}$, the thermal conductivity of the material does not change under standard conditions. From the point of view of thermal insulation of structures, it is important to determine the thermal conductivity of PIR at negative temperatures, for which further studies are carried out.

- The removal of the facing results in up to $8 \%$ greater change in thermal conductivity after exposure to high temperatures, compared to specimens faced with diffusion tight facings. The application of diffusion tight film to the sides of the specimens does not affect the change in thermal conductivity of the specimens after aging, because it is not as tightly pressed to the foam core as for factory made faced insulation boards. 
- The results of this study are important to get knowledge about the aging of PIR insulation when it is installed in building envelope, so further research is being conducted on different facing materials on boards open ends to select a reliable technology to prevent thermal conductivity increase through the open ends (e.g. wall corners).

\section{ORCID}

Tomas Makaveckas: https://orcid.org/0000-0002-0643-7807

Raimondas Bliūdžius: https://orcid.org/0000-0003-4703-1106

Aurelija Levinskytė: https://orcid.org/0000-0002-7295-8045

\section{References}

Alvey, B. J., Patel, J. and Stephenson, D. L. (2017). Experimental study on the effects of humidity and temperature on aerogel composite and foam insulations. Energy and Buildings, 144, 358-371. doi: 10.1016/j.enbuild.2017.03.070

Berardi, U. and Naldi, M. (2017). The impact of the temperature dependent thermal conductivity of insulating materials on the effective building envelope performance. Energy and Buildings, 144, 262-275. doi: 10.1016/j.enbuild.2017.03.052

Berardi, U. (2017). The impact of temperature dependecy of the building insulation thermal conductivity in the Canadian climate. Energy Procedia, 132, 237-242. doi: 10.1016/j.egypro.2017.09.684

Berardi, U. (2019). The impact of aging and environmental conditions on the effective thermal conductivity of several foam materials. Energy, 182, 777-794. doi: 10.1016/j.energy.2019.06.022

Bogdan, M., Hoerter, J. and Moore, F. O. Jr. (2005). Meeting the Insulation Requirements of the Building Envelope with Polyurethane and Polyisocyanurate Foam. Journal of Cellular Plastics, 41, 41-56. doi$10.1177 / 0021955 \times 05049869$

Building Science Corporatio values for Polyisocyan

Christian, J. E., Desjarlais, Standard for Estimating Polyisocyanurate In
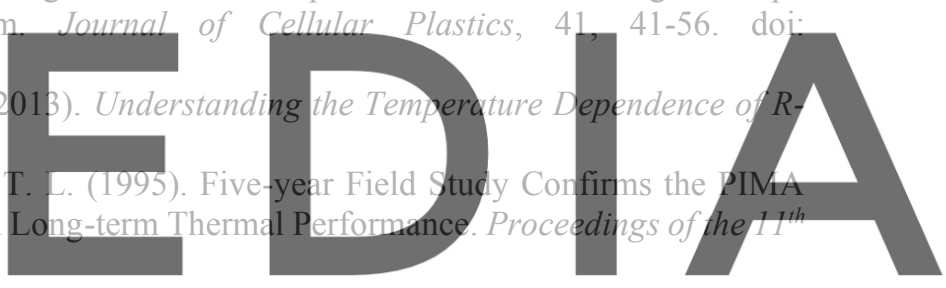

EN 13165:2012+A2 (2016). Thermal insulation products for buildings - Factory made rigid polyurethane foam

Register for (PU) products-Specification. Membrane Colour in Canada. Proceedings of the $14^{\text {th }}$ Canadian Conference on Building Science and Technology

Jin, J., Dong, Q., Shu, Z., Wang, W. and He, K. (2014). Flame retardant Properties of Polyurethane/expandable Praphite Composites. Procedia Engineering, Nr. 71. 304-309. doi: 10.1016/j.proeng.2014.04.044

Khoukhi, M., Fezzioui, N., Draoui, B. and Salah, L. (2016). The impact of changes in thermal conductivity of polystyrene insulation material under different operating temperatures on the heat transfer through the building envelope. Applied Thermal Engineering 105, 669-674. doi: 10.1016/j.applthermaleng.2016.03.065

Mukhopadhyaya, P., Bomberg, M. T., Kumaran, M. K., Drouin, M., Lackey, J., Reenen, v. D. and Normandin, N. (2004). Long-Term Thermal Resistance of Polyisocyanurate Foam Insulation with Gas Barrier. Proceedings of the Buildings IX (ASHRAE)

Paraschiv, S. L., Paraschiv, S. and Ion, I. V. (2017). Increasing the energy efficiency of buildings by thermal insulation. Energy Procedia 128, 393-399. doi: 10.1016/j.egypro.2017.09.044

Singh, S. N., Ntiru, M. and Dedecker, K. (2003). Long Term Thermal Resistance of Pentane Blown Polyisocyanurate Laminate Boards. Journal of Cellular Plastics, Vol. 39, 265-280. doi: $10.1177 / 002195503035065$

Stovall, T., Vanderlan, M. and Atchley, J. (2013). Evaluation of Experimental Parameters in the Accelerated Aging of Closed-Cell Foam Insulation: Results after Five Years of Full-Thickness Aging. Proceedings of the Thermal Performance of the Exterior Envelopes of Whole Buildings XII International Conference (ASHRAE)

Zhang, H., Fang, W., Li, Y. and Tao, W. (2017). Experimental study of the thermal conductivity of polyurethane foams. Applied Thermal Engineering, 115, 528-538. doi: 10.1016/j.applthermaleng.2016.12.057 